\title{
Primary health care: a review of its implementation in sub-Saharan Africa
}

\author{
Rufaro Richard Chatora and P. Tumusime WHO Regional Office for Africa, Brazzaville, Republic of Congo
}

\begin{abstract}
Health for all was identified by the World Health Assembly in 1977 as the desirable main social target for governments, international agencies and the global community. Primary health care was defined at Alma Ata in 1978 and was then seen as the vehicle to achieving health for all. Governments in sub-Saharan Africa embarked on processes to align their health policies and indeed implement them within the PHC framework. PHC in Africa was seen as an overall strategy for achieving health for all, rather than just as the first level of care. Thus countries restructured their entire health systems in the framework of PHC rather than focus on the first level of care only. The mid to late 1980s saw worsening economic performance which was followed by the enforcement of structural adjustment programmes, sociopolitical instability, man-made and natural disasters and the beginning of the HIV/AIDS pandemic. All these wrecked havoc on plans countries had for implementation of PHC. Within this context, the elaborate policies and plans were not fully implemented. Furthermore, there appears to have been a general underestimation of the resources required. Though there was some initial progress in improving health status as shown by some health parameters, health for all was not achieved by any of the countries.
\end{abstract}

Key words: primary care; sub-Saharan Africa

\section{Introduction}

The World Health Assembly in 1977 resolved that countries, international agencies and the global community should work towards attainment of all the peoples of the world of a level of health that would permit them to lead a socially and economically productive life, later known as 'health for all'. The International Conference on Primary Health Care (PHC), held at Alma Ata in 1978 defined PHC (WHO/UNICEF, 1978). Inherent in the definition were the principles of PHC which included universal access, equity, community participation and intersectoral action. The conference identified core elements of PHC, which in today's terminology can be seen as the essential package of services, this included education concerning prevailing health problems and

Address for Correspondence: Rufaro Richard Chatora, WHO Regional Office for Africa, Box 6, Brazzaville, Republic of Congo. E-mail: chatorar@email.com methods for preventing them; promotion of food supply and proper nutrition; supply of safe water and basic sanitation; maternal and child health, including family planning; immunization against major infectious diseases; prevention and control of locally endemic diseases; appropriate treatment of common diseases and injuries and provision of essential drugs.

At the time the PHC philosophy was born, the majority of African countries had attained their independence. They had inherited health systems which were developed primarily to serve the urban elite and left vast tracts of land especially in rural areas uncovered, the poor, who lived in these remote areas were thus the most adversely affected. These health systems tended to be more curative oriented and the people's participation was minimal. PHC was thus seen as providing opportunities to resolve these issues and was embraced as the guiding strategy in health development. Within this context, PHC was seen not as a level of service provision, but as an overall health strategy. 
This paper presents major findings of a review of PHC and its implementation in sub-Saharan Africa. The motivating factor for the review was the concern expressed by countries, stakeholders and their development partners involved in health development that health status was worsening and health systems were not performing effectively.

The main questions to be answered by the review were as follows:

- How were health policies in the context of PHC formulated?

- What was the socioeconomic and political environment like?

- How did policy implementation proceed?

- What resources were available for PHC?

- What were the health outcomes of this process?

- What are the lessons learnt and how best do countries carry this work forwards.

The review was carried out at country level, as well as regional level. Seventeen out of 46 countries undertook national reviews. The regional level review consisted of a literature review as well as unstructured interviews with key informants such as policymakers, professionals and other types of health workers, representatives from other sectors, community leaders, NGOS and private sector representatives in selected countries.

\section{Economic, social and political environment since Alma Ata}

Discussions on PHC at the international level, as well as locally within countries in the late 1970s assumed a conducive economic and sociopolitical environment for PHC implementation. Regrettably, the next two decades saw a deteriorating environment in sub-Saharan Africa.

Economic performance was poor in the 1980s, positive growth was registered at $0.3 \%$ as from 1993 and was highest around 1997 at about 4.7\% and began to fall and stood at 2.7 in 2000 (World Bank, 2000). High external debt has remained an obstacle to economic development. The total external debt rose from US\$ 80 billion in 1982 to US\$ 350 billion in 1998. In many countries debt servicing now exceeds $30 \%$ of export earnings (UNDP 2001). Thus, in 1996, 33 of the 41 countries classified as highly indebted poor countries were from sub-Saharan Africa. The region has continued to see its share of the global economy decrease, where there has been economic growth, there has been no meaningful investment. Official bilateral and multilateral assistance has continued to decline. Poverty, which is a hindrance to health development as well as a consequence of poor health has continued to increase with more than half of the population classified as poor (WHO, $2001 \mathrm{~b})$. Health spending as a proportion of gross domestic product (GDP) averaged $4.1 \%$ with relatively richer countries, such as South Africa spending 10.3 per cent, while the lowest spenders such as Democratic Republic of Congo spent $1.6 \%$ of GDP (World Bank, 2001b).

The region continued to face inequalities in access to basic social services such as housing, safe water and sanitation, education and health with more than $50 \%$ of the population in most countries having no access to health services (UNDP, 2000). Food security has worsened, 17 countries experienced food emergencies due to a mixture of various conditions such as drought and civil strife (FAO, 2001). Food prices have gone up, consequently malnutrition has also increased ranging between 25 and $50 \%$ in children between 1995 and 2000 (UNDP, 2001).

The escalation of political instability, armed conflict and civil war has disrupted economic activities and delivery of basic social services. At any one time, as many as 20 to 25 of the 46 countries were considered to be facing one type of emergency or another. All this results in displacement of millions of people who then require special arrangements for provision of food, housing, education and health services thus further causing severe strain to already stressed systems in host countries.

\section{Health policy formulation in the context of PHC}

\section{PHC orientations}

A review of national health policy and development plans shows that there were clear attempts to abide by the orientations of the PHC strategy. Botswana's five-year national development plans developed since the early 1980s clearly specified their goal of achieving health for all through the primary health care strategy. Burkina Faso 
adopted PHC as a core strategy for health development, and PHC was an entry point for the national health development plans developed in the country (1986-90, 1991-95). The effective launching of PHC in the Democratic Republic of Congo took place in 1985, while in Malawi, the PHC approach has been emphasized in the country's development plans, and the country's national health plan (1986-95) integrates the PHC approach as the main strategy of achieving health for all. In 1984, the Ministry of Health in Guinea developed a national health policy adapting PHC to the national and regional specificities. In Namibia, the PHC approach has been clearly articulated in the health policy documents. In addition, the launching of the community based health care (CBHC) guidelines in 1992, has increasingly indicated the government's commitment to PHC. The Tanzania health policy is commensurate with PHC and this is clearly indicated in its long term development plan for the period 1980 to 2000.

\section{Policy formulation process}

Health policy formulation followed a participatory process. In Zambia, for example, policy formulation started by establishing the National Coordinating Committee which drew members from the United National Independence Party (the political party in power at the time), the churches' medical association, and relevant government ministries such as Agriculture and Water Development; Education; Information and Broadcasting; Finance; and Community Development (Kasonde and Martin, 1994).

In 1979, the government of Burkina Faso adopted PHC, adhesion to the strategy being manifested by development of national health planning that took into account community participation in the organization and management of health services and intersectoral collaboration. This National Health Policy adopted in 1980 served as the reference framework for implementation of PHC for a period of 20 years. In September 1993, in the framework of implementation of the Bamako Initiative, a national document on strengthening PHC was developed. Real technical decentralization started with creation of 53 health districts and provision of autonomy for management of hospitals and peripheral health facilities.
At the WHO Regional Committee meeting in Bamako, Mali, in 1987, the ministers of health adopted an innovative strategy for intensification of PHC. The Bamako Initiative (BI) had four objectives, which were to:

1) Revitalize and extend peripheral health systems to provide a basic package of services;

2) Ensure adequate supply of essential drugs at reasonable cost;

3) Use community co-financing mechanisms in order to ensure sustainability; and

4) Involve communities in management of health centres.

A review of the Bamako Initiative in 1999 showed that while it has proven its usefulness there were many challenges which constrained implementation, such as low management capacity of communities, lack of human resources at operational level and financial barriers for the poor to access services (Monekosso, 1989; WHO/ Government of Mali/Unicef 1999).

\section{PHC strategy implementation}

We will examine the extent to which countries followed the orientations provided in the PHC strategy and how this was reflected in implementation. It is recognized that though there are interlinkages between different principles and elements, features of implementation of each of them is done separately to highlight specificities.

\section{Universal access}

As stated earlier, countries did not only focus on primary care in restructuring their health systems, but saw PHC as a strategy which impacted on the whole health system. In this context, countries, perhaps based on their geographical sizes developed a two-, three- or four-tier health system. Figure 1 provides a generalized example of the interlinkages between the level of care, management structures and intersectoral coordinating bodies. The first level of contact for the community with the formal health system was seen as the primary care level and the health facility at that level is the health centre or clinic. The first referral level or secondary care level was the district hospital, in some countries there were other 
$\underline{\text { Level of Care } \quad \text { Management Structure }}$

Intersectoral Coordination $\underline{\text { Body }}$

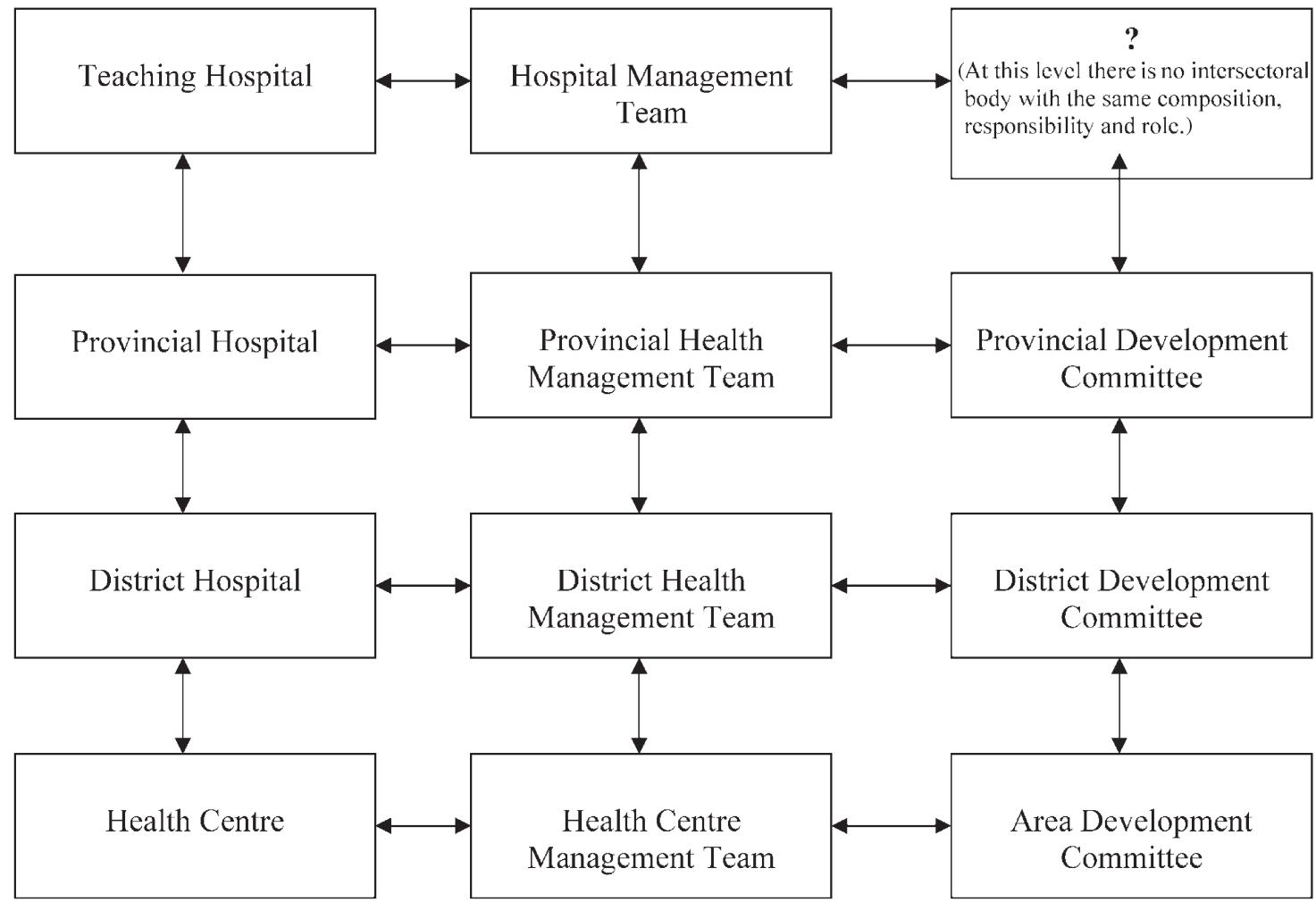

Figure 1 Hierarchical Health Care System

levels such as the regional or provincial level as well as the central level. Appropriate technical and intersectoral management structures were set up at each level.

Countries, depending on national specificities set guidelines for establishment of different types of health facilities. For example, health centres would in some countries be set up so that each serves 5000 to 10000 people or such that those in the catchment area would not have to travel more than $8 \mathrm{~km}$ or one hour travel time to reach the nearest health facility. Different guidelines were set for urban areas taking cognizance of population density. The complexity of services provided at each level determined the staff skill mix and technology required.

This new health system was based on a hierarchical structure thus theoretically, patients would have to use lower levels first and be referred to higher levels as necessary. Later on it became necessary to enforce this system and incentives were put in place to make it work. In this context, those not using the appropriate level of care were asked to pay for services if they were not referred. Service delivery was expected to be in an integrated manner to avoid missing opportunities for vaccination of children or antenatal care.

\section{Equity}

The restructured health systems were meant to ensure services would be provided for the disadvantaged and the poor, thus addressing inequity. However, by all accounts, inequity has continued and worsened in many countries. This is shown by differences in health status between urban and rural areas, between the rich and the 
poor, as well as by distribution of health resources where the rich or those living in urban areas consume more resources than the poor or those living in rural areas, respectively (Castro-Leal et al., 2000). For example, immunization coverage for the richest quintile for sub-Saharan countries is $62 \%$ compared with $32 \%$ for the poorest quintile, for antenatal care coverage it is $91.6 \%$ compared with $50.2 \%$ for the richest and poorest quintile, respectively. Concerning consumption of government subsidized health care, the richest quintile consumes $30 \%$ while the poorest quintile consumes 12\% (Carr, 2004).

\section{Community participation}

Community participation was seen as a process of involving the community by promoting dialogue with and empowering them to identify their own problems and solve them. This was demonstrated by formation of community health committees or involvement of community members in different types of health management bodies at different levels of the health system. Community health workers, such as village health workers, were trained to contribute to community mobilization, as well as provide some basic health services. Communities also contributed their labour or resources in health-related projects, such as construction of health centres, staff houses or paid for services received.

To a large extent, community participation can be seen as having been a success and a forerunner to many initiatives calling for involvement of the people. People's involvement is now an acknowledged feature of day-to-day life in the region, for example there are structures, such as public health advisory bodies, hospital management bodies and others, where community representation is seen as the norm rather than the exception. There are, however, serious issues to be addressed such as to move towards involvement and respect of decisions by the people rather than just using them to validate or legitimize health professionals' actions. A further challenge is capacity within community members to deal with and take decisions on some of the very complex issues related to health.

\section{Intersectoral collaboration}

Beyond the health sector, many other sectors such as education, agriculture, housing, water, community development, among others significantly contributed to producing health. Thus, there is need to have a close working relationship with them. In this regard, intersectoral collaboration committees were formed at different levels of the health system. In some countries, development committees were set up to deal with all development issues at district and regional levels. Sector specific collaboration committees were set up usually being subcommittees of the development committees.

Similar challenges as those met with regards to community participation have been met. It also seems that though all sectors commit to collaboration, each one of them wants collaboration to be on its terms, in many cases, the health sector has called others to discuss health issues, but would not accept different views. In some cases, the health sector has gone ahead and set up parallel structures and spent resources to undertake work that could have been better done by another sector. Examples are the nutrition projects run by the Ministry of Health, while the ministry responsible for agriculture has better capacity to carry out the work.

\section{Elements of PHC}

Education concerning prevailing health problems and the methods of preventing and controlling them

Education concerning health problems and methods of preventing and controlling them addresses the broad determinants of health that underlie the burden of disease and ill-health in the region, with the aim of promoting health. According to a WHO survey carried out in September 2000, assessing how countries have approached this, out of a total of 37 countries responding, 15 used health education; 11 used information, education and communication; five used health promotion; two used information, education and communication and health education; one used information, education and communication and social mobilization; while two had used no specific approach.

In 2001, countries adopted a health promotion strategy aimed at fostering actions that enhance the physical, social and emotional well-being of the people and contribute to the prevention of leading causes of disease, disability and death. 
Promotion of food supply and proper nutrition

Advocacy for food supply and proper nutrition not only came through PHC but also through work done by international agencies such as Food and Agriculture Organization (FAO). Many of the policies pursued by African countries during the 1970s and 1980s successfully achieved aggregate national food security, but did not achieve adequate consumption by all individuals and groups within the country (WHO, 2001a). To meet domestic demand, maximize food production and increase marketed supplies of food, many African countries later embarked on food security strategies focused on achieving food self-sufficiency.

The availability of basic food staples for consumption has expanded by $30 \%$ for cereals and cereal products, $40 \%$ for roots and tubers, $35 \%$ for pulses, and $35 \%$ for oil crops. However, the estimated annual rate of population growth for the last three decades was about 3\% compared with a rate of growth in food production of around 2\% (WHO, 2001a).

Data from FAO show that in Africa, the proportion of chronically undernourished people rose from 38 to $43 \%$ between 1969 and 1992. Anaemia affects another 206 million people, while for iodine deficiency disorders and vitamin A deficiency, 181 million and 52 million are at risk.

Adequate supply of safe water and basic sanitation

The majority of countries previously drew their water and sanitation policy guidance from general development policies, national development plans, or in some cases water legislation; very few had formal water and sanitation policies. Recognition of the importance of water and sanitation as advocated by PHC led countries to prioritize work in this area.

During the international drinking water and sanitation decade, 1981 to 1990 , plans were prepared for nearly all countries of the Region, setting out their national needs, priorities, goals and targets. Innovative approaches to improving water supply through protection of natural and hand dug wells, springs and machine dug boreholes, as well as improving sanitation through use of improved ventilated pit latrines, such as the Blair toilet developed in Zimbabwe were undertaken (Morgan and Mara, 1985). This was a good example of intersectoral action as this brought together sectors responsible for health working hand in glove with those responsible for water and public works.

Water and sanitation coverage increased markedly, from $32 \%$ water coverage in 1980 to $56 \%$ in 1999, and from $28 \%$ sanitation coverage in 1980 to $55 \%$ in 1999 (WHO, 2000).

\section{Maternal and child health care, including family planning}

The health of mothers and children is at the center of regional efforts to improve health, $\mathrm{PHC}$ was seen as an opportunity towards that objective. National health policies developed in the context of PHC, as well as health sector reforms had explicit targets for maternal and child health. Unfortunately, progress has been slow. Recently, strategies have been adopted to accelerate reduction of maternal and perinatal mortality and disability (WHO, 1998). This focuses on improving access to antenatal care; provision of hospital-based treatment of pregnant women with life-threatening complications; transport and communication; and strengthening of the health care system.

In order to reduce the high infant and child mortality rates, most countries including Benin, Botswana, the Democratic Republic of Congo, Ghana, Kenya, Madagascar, Malawi, Niger, Tanzania, Togo, Zambia and Zimbabwe, have adopted an integrated approach for child health programmes that go beyond single diseases and address the overall health of a child. Recent measures and strategies that have been adopted in the area of child health include: the continuation of national immunization campaigns to eradicate major childhood diseases in all countries reviewed; the promotion of breast feeding; the formulation and implementation of a nutrition policy; the free health care for pregnant mothers and children under the age of 6 years and free treatment for malnutrition and diarrhoeal diseases. The adoption of the WHO/ UNICEF approach for integrated management of childhood illness (IMCI) (WHO/UNICEF, 1999) is seen as a great achievement in reducing childhood death and illness (WHO, 2001a).

\section{Immunization against the major infectious diseases}

A major success of PHC in the region is demonstrated by how countries and partners worked together to prevent childhood vaccine preventable 
diseases. Child immunization coverage has increased remarkably in most countries, with almost two-thirds of all children under 1 year immunized. UNICEF notes that 3 million fewer children under 5 now die each year, due in large part to immunization programmes and the dedicated efforts of families and communities (United Nations Children's Fund, 2001). Figure 2 shows the trend in the immunization coverage from 1982 to 2001. Immunization programmes have improved accessibility of immunization through increased public education on the value of PHC.

Immunization against tetanus among women of childbearing age is far below expected coverage. For example, in the Central African Republic, the coverage of pregnant women with two or more doses of tetanus toxoid during the period 1991 to 2001 ranged between only 14 and 32\% (Enquête CV OMS, 1990-1991; EDS, 1994-1995; Enquête MICS, 1996; Données de routine de 1997 à 1999; MICS, 2000; Revue PEV, 2002), while in Niger between 1994 and 1999 it ranged from $27 \%$ to $42 \%$ (Rapports annuels d'activités DNPEV) (Niger/Unicef, 2003). Cases of neonatal tetanus still exist.
Prevention and control of locally endemic diseases

Prevention and control of endemic diseases, was largely focused on communicable diseases, but in the last decade or so now includes noncommunicable diseases like cardiovascular diseases, cancers and mental illness.

Countries have adopted strategies for prevention and control of communicable and noncommunicable diseases with the aim of strengthening the country capacity to draw up policies and implement programmes using comprehensive multisectoral approaches. Examples are Roll Back Malaria (RBM), the HIV/AIDS strategy and directly observed therapy (DOTS) for TB. Success has been variable. A good example is TB where the number of countries using DOTS has been increasing since the early 1980s reaching 41 out of 46 by 1998 . Fifty-six per cent of the countries have attained $100 \%$ population coverage. Technical, managerial and financial support has been provided to countries towards elimination of leprosy and measles, and eradication of polio and guinea worm disease. Through the integrated disease surveillance programme, there has been improvement in priority

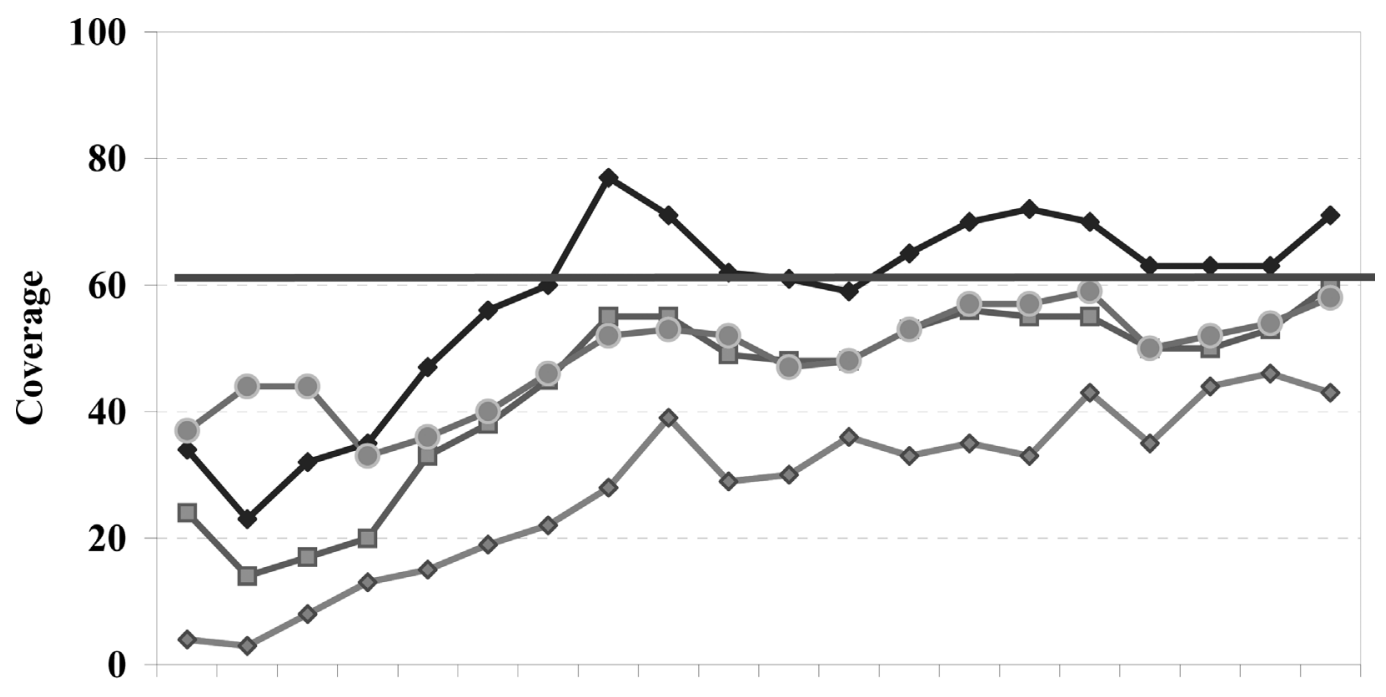

$\begin{array}{llllllllllllllllllll}82 & 83 & 84 & 85 & 86 & 87 & 88 & 89 & 90 & 91 & 92 & 93 & 94 & 95 & 96 & 97 & 98 & 99 & 00 & 01\end{array}$

$\leadsto$ BCG $\because-$ DPT3 $-\bullet-$ Measles $\leadsto$ TT2

Figure 2 Immunization coverage with EPI vaccines in the sub-Saharan African Region, 1982-2001 Source: AFRO, 2002 
setting, planning, resource mobilization and allocation, prediction and early detection of epidemics and monitoring and evaluation of intervention programmes.

\section{Appropriate treatment of common diseases and injuries}

The health policies adopted and the infrastructure development work carried out, as discussed earlier in this paper, have been towards ensuring access to services and enable treatment of common diseases and injuries. Countries have worked hard to improve the diagnosis and treatment of diseases and injuries, in accordance with improving technology. Available guidelines and tools to facilitate identification of standard equipment and other technologies have been used by countries. Most countries have adopted the syndromic management approach in areas like sexually transmitted infections.

\section{Provision of essential drugs}

In order to increase access to essential drugs, countries formulated and implemented national drug policies using WHO guidelines provided for that purpose. At present 38 countries have used these guidelines to start the process of formulating or reviewing their national drug policies, and 33 of them now have official national drug policies. In spite of these efforts, it is estimated that over $50 \%$ of the population do not have regular access to the most basic essential drugs. The reasons for this include inadequate financing for health in general and for drugs in particular. Even when drugs are available, weak regulatory capacity may mean that they are substandard or counterfeit, and that they are not rationally used. Working with their partners countries are now focusing on policy, access, quality and safety, and rational use of drugs. Among these, greatest emphasis is on securing access to essential drugs for priority health problems, such as malaria, childhood illnesses, tuberculosis and HIV/AIDS.

Traditional medicine maintains its popularity for historical and cultural reasons. In Benin and Sudan, for example, $70 \%$ of the population rely on traditional medicine. In Ghana, Mali, Nigeria and Zambia, $60 \%$ of children with fever were treated with herbal medicines at home in 1998.
Some countries are producing locally, on a pilot scale, various plant-based preparations for chronic diarrhoea, liver disorders, amoebic dysentery, constipation, cough, eczema, ulcers, hypertension, diabetes, mental health and HIV/AIDS. Some of these medicines have been registered and included in the national essential drug lists. Countries have prioritized and are institutionalizing traditional medicine in national health systems and are undertaking the rational scientific assessment of traditional herbal medicines.

\section{Other elements}

In addition to these eight elements, some countries added a few more depending on need. Kenya, for example, added a blindness prevention programme and a mental health programme. Other countries included care of the elderly and dental health.

\section{PHC resources}

\section{Health infrastructure}

A network of infrastructure to support PHC service delivery has been developed; depending on the country, this includes health posts, dispensaries, rural maternity and health centres. Health centres play the role of interface between the population and the higher-level facilities, such as district and other referral hospitals. These structures serve about $80 \%$ of the population, but regrettably receive at best only $20 \%$ of the financial resources of the health system (Eastern and Southern Africa National Health Accounts Network, 2001). Figure 3 showing consolidated data from national health accounts of some countries in eastern and southern africa confirms this point. Primary care facilities are very often short of equipment and qualified personnel, and are unable to undertake appropriate management procedures. Their dysfunction contributes significantly to the poor performance of the health systems noticed in almost all the countries.

However, the importance of hospitals needs to be underscored. Their key role in provision of referral care, development of human resources for health in terms of training and supervision, and information and research, needs to always be highlighted as a vital link with the lower 


\section{Comparison of hospital and primary care expenditure as a percentage of total expenditure}

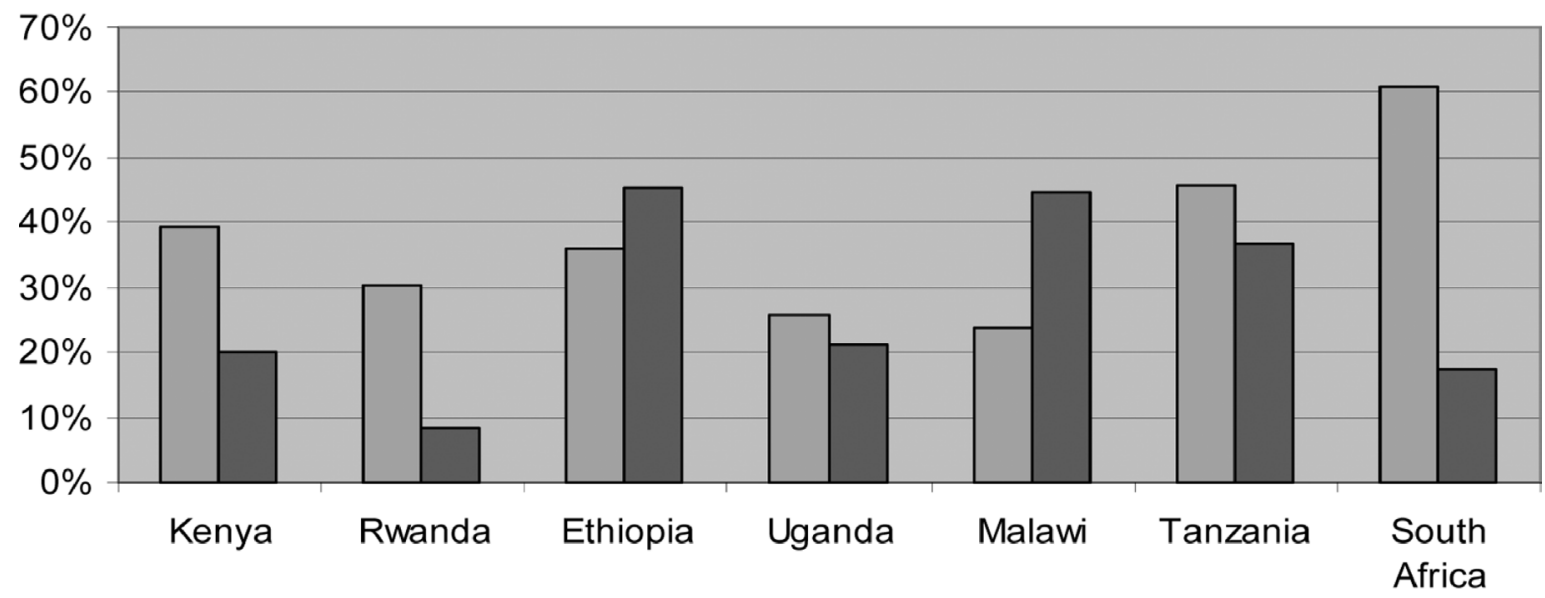

Hospitals $\square$ Primary Care (Non Hospital)

Figure 3 Allocation of expenditure by level of care: Hospital and non-hospital care, 1997/98. Source: Eastern and Southern Africa NHA Network, 2001: National health accounts in eastern and Southern Africa. A comparative analysis (Unpublished report)

levels in health care delivery. Despite seemingly consuming the greater share of the health budgets, the hospitals are underfunded and commonly found to be dilapidated, without equipment, drugs and other essential supplies. Human resources for proper hospital management are also lacking.

\section{Human resources}

Health personnel salaries consume $50-75 \%$ of recurrent health budgets in most countries (United Nations Children's Fund 2001). Most countries have also trained and utilized community health workers (CHW) to promote the delivery of basic, cost-effective services to the majority of the people.

PHC has implications on human resources in terms of both training and practice. Unfortunately training and education of health workers remains elitist and hospital focused, producing cadres not appropriately equipped to deal with health promotion and preventive care. There is clearly a need for a shift from the "medical para- digm' to a 'health paradigm' more geared to promotion of health and well-being.

Although in some countries, such as Cape Verde, the human resources/population ratios for medical doctors and nurses could be considered to be good, the shortage of trained and qualified health human resources in Africa continues to be a major impediment to PHC development. Another major drawback is the scarcity of health personnel in the public health delivery systems. Countries have introduced various types of policies to retain skilled staff, Lesotho and Zimbabwe, for example have implemented bonding whereby workers are obliged to work at certain institutions for an agreed length of time, while many others have raised public sector salaries.

The situation of internal migration as well as out-migration has reached crisis levels. A study undertaken in 2002 (Awases et al., 2002) showed that $26-68 \%$ of health workers interviewed intend to migrate to other countries. The main push factors for migration were poor salaries, poor working conditions, lack of opportunities for professional development, unclear career 
Table 1 Distribution of health workers by gender and by zone in Niger

\begin{tabular}{|c|c|c|c|c|c|c|c|c|c|c|c|c|c|c|c|c|c|c|}
\hline & \multicolumn{2}{|c|}{ Agadez } & \multicolumn{2}{|c|}{ Diffa } & \multicolumn{2}{|c|}{ Dosso } & \multicolumn{2}{|c|}{ Maradi } & \multicolumn{2}{|c|}{ Tahoua } & \multicolumn{2}{|c|}{ Tillabéry } & \multicolumn{2}{|c|}{ Zinder } & \multicolumn{2}{|c|}{ Niamey } & \multirow[t]{2}{*}{ Total } & \multirow[t]{2}{*}{$\%$} \\
\hline & $\mathrm{M}$ & $\mathrm{F}$ & $M$ & $\mathrm{~F}$ & $M$ & $\mathrm{~F}$ & $M$ & $\mathrm{~F}$ & $M$ & $\mathrm{~F}$ & $M$ & $\mathrm{~F}$ & $M$ & $\mathrm{~F}$ & $M$ & $\mathrm{~F}$ & & \\
\hline & 94 & 60 & 65 & 29 & 104 & 82 & 114 & 105 & 127 & 76 & 53 & 36 & 172 & 168 & 660 & 851 & 27 & $65 \%$ \\
\hline Col & 26 & 37 & 43 & 22 & 134 & 89 & 191 & 76 & 163 & 93 & 160 & 146 & 222 & 132 & & & & $35 \%$ \\
\hline Tota & 120 & 97 & 108 & 51 & 238 & 171 & 305 & 181 & 290 & 169 & 213 & 182 & 394 & 300 & 660 & 851 & 4350 & $100 \%$ \\
\hline
\end{tabular}

Source: Développement des resources humaines pour la Santé, plan stratégique: 2000-2010, Septembre 1999.

paths, conflicts and wars. Migration of skilled health workers contributed significantly in deteriorating access to and quality of care in the region.

Worse still, in addition to the shortage of human resources for health, there is often inequitable distribution of available human resources. In Niger, the breakdown by zone demonstrates the important disparities and confirms the concentration of health personnel in urban areas (Table 1). For example, in Niamey, the capital city of Niger, are found $60 \%$ of all doctors, $50 \%$ of all midwives and $30 \%$ of all nurses in the country.

Human resources for health in sub-Saharan Africa has now become an issue of major concern and countries are now designing national and global approaches to addressing the challenge.

\section{Health financing}

The major source of financing health care goods and services is the government general tax revenue contributing on average $42.6 \%$, while households through direct out of pocket payment mechanisms are the second source contributing an average of $36.7 \%$ of the total health expenditure. Donors contribute an average of $15 \%$ of total health spending (WHO, 2003a).

Much as there is inefficiency and inequity in resource allocation and utilization as noted by the few resources allocated to $\mathrm{PHC}$, it should be noted that most countries' national health systems face an absolute inadequacy of financial resources, as well as poor allocation of resources.

The total expenditure ranges from a low of US\$ 3 per capita in Liberia and Burundi to a high of US\$ 440 per capita in the Seychelles in 2000. Only 10 countries spend more than US\$30 as recommended by the Commission on Macroeconomics and Health Report of 2001 for providing essential health interventions.

\section{Conclusion}

At the adoption of the primary health care strategy by the World Health Assembly, there was a great deal of expectation that this approach would help address some of the major challenges health systems were facing. Many countries adopted health policies for implementation of PHC.

The economic crises, wars and political instability, HIV/AIDS and the emergence of new or re-emergence of old communicable diseases provided an unsupportive environment for implementation of PHC. Furthermore, it also became apparent that $\mathrm{PHC}$ was not as economical as many had expected, thus many countries could not afford to provide the resources required for full implementation. There were also difficulties with human and institutional capacity to implement the programmes. The end result is as we know today that countries were not able to achieve 'health for all', however defined. The approach and its principles, however, are seen as being still very relevant. Thus in 2000, countries committed themselves towards reviewing and updating their health policies in line with the regional orientations for health for all for the twenty-first century in the African region.

\section{Acknowledgement}

The review was undertaken as part of our work at the WHO Regional Office for Africa. 


\section{References}

Awases, M., Gbary, A., Nyoni, J. and Chatora, R. 2002: Report on the migration study in the African region. Brazzaville. WHO Regional Office for Africa.

Castro-Leal, F., Dayton, J., Demoy, L. and Mehra, K. 2000: Public spending on health care in Africa: do the poor benefit? Bulletin of the World Health Organization 78 (1) 66-74.

Carr, D. 2004: Improving the health of the world's poorest people. Health Bulletin 1, (Population Reference Bureau).

Food and Agriculture Organization of the United Nations. 2001: The state of food and Agriculture Rome: FAO.

Kasonde, J. and Martin, J. editors, 1994: Experiences with primary health care in Zambia. Geneva: World Health Organization.

Monekosso, G.L. 1989: The Bamako Initiative: community selffinancing of primary health care through the supply and cost recovery of basic essential drugs, some guiding principles. Brazzaville: WHO, Regional Office for Africa, 8 pp.

Morgan, P. and Mara, D. 1985: Ventilated improved pit latrines: Zimbabwean brick designs. Washington, DC: The World Bank.

Niger/Unicef. 2003: Enquête MICS 2. Décembre 2003.

United Nations Children's Fund. 2001: Annual report 2001. New York: Unicef, 32 pp.

United Nations Development Programme. 2000: Human development report 2000: Human rights and human development. New York: UNDP.

United Nations Development Programme. 2001: Human development report 2001: Making new technologies work for human development. New York: UNDP.

WHO/Government of Mali/Unicef. 1999: Report on the review of the implementation of the Bamako initiative in Africa, Bamako (Mali) 8-12 March 1999. Harare: WHO Regional Office for Africa, $35 \mathrm{pp}$.

WHO/UNICEF 1978: Declaration of Alma-Ata. In: International Conference on Primary Health Care, Alma-Ata, USSR, 6-12 September 1978. Geneva: World Health Organization.

WHO. 1998: Regional Office for Africa. Reproductive health: strategy for the African Region 1998-2007. Harare: WHO Regional Office for Africa, 20 pp.

WHO. 2000: Regional Office for Africa. Water supply and sanitation sector assessment 2000: African Region Part 2, Country Profiles. Harare: WHO Regional Office for Africa.

WHO. 2001a: Regional Office for Africa. Integrated management of childhood illness (IMCI): strategy for 2000-2005. Harare: WHO Regional Office for Africa, $10 \mathrm{pp}$.

WHO. 2001b: Macroeconomics and health: investing in health for economic development: report of the Commission on Macroeconomics and Health. Geneva: World Health Organization.

WHO. 2003a: Regional Office for Africa. Health promotion: a strategy for the African Region. Brazzaville: WHO Regional Office for Africa, $10 \mathrm{pp}$.

WHO. 2003b: World Health Report 2003, shaping the future. Geneva: World Health Organization.

World Bank. 2000: Annual report 2000. Washington: World Bank.

World Bank. 2001: Annual report 2001. Washington: World Bank. 